\title{
Phylogenetic relationships of the genus Kluyvera: transfer of Enterobacter intermedius Izard et al. 1980 to the genus Kluyvera as Kluyvera intermedia comb. nov. and reclassification of Kluyvera cochleae as a later synonym of K. intermedia
}

Correspondence Jorge Zorzopulos zorzopul@hotmail.com

\author{
María E. Pavan, ${ }^{1}$ Raúl J. Franco, ${ }^{1}$ Juan M. Rodriguez, ${ }^{1}$ Patricia Gadaleta, ${ }^{2}$ \\ Sharon L. Abbott, ${ }^{3}$ J. Michael Janda ${ }^{3}$ and Jorge Zorzópulos ${ }^{1,2}$ \\ ${ }^{1}$ Instituto de Investigaciones Biomédicas Fundación Pablo Cassará, Saladillo 2452, \\ Buenos Aires (1440), Argentina \\ ${ }^{2}$ Departamento de Química Biológica, Facultad de Ciencias Exactas y Naturales, \\ Universidad de Buenos Aires, Argentina \\ ${ }^{3}$ Microbial Diseases Laboratory, Division of Communicable Disease Control, \\ California Department of Health Services, Richmond, CA, USA
}

\section{INTRODUCTION}

Despite their great medical and economical importance, the bacteria included in the family Enterobacteriaceae are still

The GenBank/EMBL/DDBJ accession numbers for the 16S rRNA gene sequences of $K$. cochleae ATCC $51609^{\top}, K$. georgiana ATCC $51603^{\top}, K$. cryocrescens ATCC $33435^{\top}, K$. ascorbata ATCC $33433^{\top}$ and Enterobacter intermedius ATCC $33110^{\top}$ are AF047187, AF047186, AF310218, AF310219 and AF310217, respectively.

A phylogenetic tree showing that members of the genus Enterobacter are intertwined with members of other genera is available as supplementary material in IJSEM Online. poorly understood phylogenetically. Furthermore, there is evidence suggesting the need for extensive revision of the taxonomic relationships among genera and species within this family. For example, based on $16 \mathrm{~S}$ rRNA trees (Drancourt et al., 2001), it has been reported that the genus Klebsiella is heterogeneous and composed of species which form three clusters that include members of other genera.

Kluyvera is a genus of small rod-shaped bacteria, thus conforming to the general definition of the family Enterobacteriaceae (Holt et al., 1994). Bacteria of this genus are mainly grouped in four known species, Kluyvera ascorbata, 
Kluyvera cryocrescens, Kluyvera cochleae and Kluyvera georgiana (Farmer et al., 1981; Müller et al., 1996).

The present study was undertaken to gain insight into the phylogenetic relationships among species within the genus Kluyvera and between the genus Kluyvera and related genera within the family Enterobacteriaceae, using $16 \mathrm{~S}$ rRNA genebased trees, DNA-DNA hybridization analysis and phenotypic characterization.

\section{METHODS}

Bacterial strains. Culture collection strains used in this study were K. cochleae ATCC $51609^{\mathrm{T}}\left(=\mathrm{CDC} 9514-94^{\mathrm{T}}=\mathrm{DSM} 9406^{\mathrm{T}}\right)$ and ATCC 51717 (CDC 9532-94=DSM 9407), K. georgiana ATCC $51603^{\mathrm{T}} \quad\left(=\mathrm{CDC} \quad 2891 \mathrm{~A}-76^{\mathrm{T}}=\mathrm{CDC} \quad 2891-76^{\mathrm{T}}=\mathrm{DSM} \quad 9409^{\mathrm{T}}\right)$, K. ascorbata ATCC $33433^{\mathrm{T}}\left(=\mathrm{CDC} 0648-74^{\mathrm{T}}\right), \quad$ K. cryocrescens ATCC $33435^{\mathrm{T}}\left(=\mathrm{CDC} 2065-78^{\mathrm{T}}\right)$ and Enterobacter intermedius ATCC $33110^{\mathrm{T}}\left(=\right.$ CUETM $77-130^{\mathrm{T}}=$ CIP $79.27^{\mathrm{T}}=$ Gavini $\left.\mathrm{E} 86^{\mathrm{T}}\right)$. Strains $77 / 123,77 / 136$ and $77 / 139$ were received from D. Old (Ninewells Hospital and Medical School, Dundee, UK) and strain CDC 9011-82 was received from the Centers for Disease Control and Prevention (Atlanta, GA, USA) as Enterobacter intermedius. Culture was performed on Luria-Bertani medium at $35^{\circ} \mathrm{C}$ under aerobic conditions.

Biochemical studies. Enterobacter intermedius and Kluyvera strains were characterized phenotypically using a battery of 43 biochemical tests in conventional media. These tests included: triple-sugar iron agar reactions; pigmentation $\left(25^{\circ} \mathrm{C}\right)$; motility; production of cytochrome oxidase, nitrate reductase and indole; growth in $\mathrm{KCN}$ broth; urea hydrolysis (Christensen's); utilization of malonate, citrate (Simmon's), acetate and mucate; production of $\beta$-galactosidase (ONPG) and phenylpyruvic acid (phenylalanine deaminase); lysine decarboxylase, ornithine decarboxylase and arginine dihydrolase (Møeller's) activities; elaboration of acetylmethylcarbinol (VogesProskauer); degradation of gelatin, corn oil (lipase), DNA and polypectate $\left(25^{\circ} \mathrm{C}\right)$; and aesculin hydrolysis (broth). Carbohydrate fermentation reactions were performed in extract broth against $1 \%$ solutions of the following carbohydrate or carbohydrate-like compounds: adonitol, amygdalin, L-arabinose, D-arabitol, cellobiose, dulcitol, methyl $\alpha$-D-glucopyranoside, D-glucose, glycerol, myoinositol, lactose, maltose, D-mannitol, melibiose, raffinose, Lrhamnose, D-sorbitol, salicin, sucrose, trehalose and D-xylose. All of these tests have been described previously (Abbott et al., 1992, 2003; Janda et al., 1996). Unless otherwise specified, tests were incubated at $35^{\circ} \mathrm{C}$ for $2-4$ days ( 7 days for carbohydrate fermentation and extracellular enzymes) and final results were recorded. Biochemical reactions presented in Tables 1 and 2 are at $48 \mathrm{~h}$ incubation.

Bacterial DNA extraction and analysis. Bacterial DNA was extracted by standard procedures and analysed using electrophoresis in agarose gels of serial dilutions of K. cochleae ATCC $51609^{\mathrm{T}}$ and Enterobacter intermedius ATCC $33110^{\mathrm{T}}$ DNA of equal concentration and Southern blot capillary transfer to nylon membranes under alkaline conditions (Sambrook et al., 1989).

DNA-DNA hybridization. The genetic relatedness among members of the genus Kluyvera was determined by DNA-DNA hybridization on nylon membranes (Johnson, 1991). Serial dilutions of cell suspensions of equal $\mathrm{OD}_{570}$ values in denaturation solution $(0.5 \mathrm{M}$ $\mathrm{NaOH} / 1 \cdot 0 \mathrm{M} \mathrm{NaCl}$ ) were applied to nylon membranes (Pall Biodyne). The membranes were then neutralized with $1.5 \mathrm{M} \mathrm{NaCl} /$ $0.5 \mathrm{M}$ Tris/ $\mathrm{HCl}(\mathrm{pH} 8)$ and fixed by UV radiation for $15 \mathrm{~min}$. Pre-hybridization $(2 \mathrm{~h})$ was performed at $65^{\circ} \mathrm{C}$ in a buffer containing $0 \cdot 15 \mathrm{M} \mathrm{NaCl}, 1 \%$ SDS and $0.3 \%$ non-fat dried milk, and
Table 1. Key reactions for Enterobacter intermedius, $K$. cochleae, K. georgiana, $K$. ascorbata and $K$. cryocrescens

1, E. intermedius ATCC $3310^{\mathrm{T}}$; 2, K. cochleae ATCC $51609^{\mathrm{T}}$; 3, K. georgiana ATCC $51603^{\mathrm{T}} ; 4, K$. ascorbata ATCC $33433^{\mathrm{T}}$; 5 , K. cryocrescens ATCC $33435^{\mathrm{T}}$. Only variable results are shown in the table. The following tests gave identical results for the five type strains: triple-sugar iron $(24 \mathrm{~h})$ (acid/acid + gas); motility $(+)$; urea hydrolysis $(-)$; ONPG $(24 \mathrm{~h})(+)$; utilization of citrate $(+)$ and acetate $(+)$; degradation of mucate $(+)$, DNA $(-)$, corn oil $(-)$ and gelatin $(-)$; polypectate $(+)$; Møeller's reaction, arginine $(-)$ and ornithine $(+)$; phenylpyruvic acid test $(-)$; fermentation of L-arabinose $(+)$, D-glucose $(+)$, L-rhamnose $(+)$, D-xylose $(+)$, cellobiose $(+)$, lactose $(+)$, maltose $(+)$, sucrose $(+)$, trehalose $(+)$, raffinose $(+)$, adonitol $(-)$, myoinositol $(-)$, D-mannitol $(+)$, salicin $(+)$, melibiose $(+)$, amygdalin $(+)$ and D-arabitol $(-)$; aesculin hydrolysis $(+)$; pigmentation $(-)$; growth in $\mathrm{KCN}$ broth $(+)$. Reactions are reported at $48 \mathrm{~h}$.

\begin{tabular}{|lccccc|}
\hline Test & $\mathbf{1}$ & $\mathbf{2}$ & $\mathbf{3}$ & $\mathbf{4}$ & $\mathbf{5}$ \\
\hline Formation of indole & - & - & + & + & + \\
Utilization of malonate & + & + & - & + & - \\
Voges-Proskauer & + & + & - & - & - \\
Lysine (Møeller's reaction) & - & - & + & + & - \\
Fermentation of: & & & & & \\
$\quad$ Dulcitol & + & + & + & - & - \\
Erythritol & - & - & - & - & - \\
Glycerol & $+\mathrm{G}$ & $+\mathrm{G}$ & $+{ }^{\mathrm{w}}$ & $+{ }^{\mathrm{w}}$ & $+\mathrm{G}$ \\
D-Sorbitol & + & + & - & - & - \\
Ascorbate & + & + & + & + & - \\
Growth on CIN $\dagger$ & + & + & + & + & - \\
& & & & & \\
\hline
\end{tabular}

${ }^{\star} \mathrm{G}$, Gas production; ${ }^{\mathrm{w}}$, weakly acidic.

$\dagger \mathrm{CIN}$, Cefsulodin/irgasan/novobiocin.

hybridization $(18 \mathrm{~h})$ was performed at $65^{\circ} \mathrm{C}$ in a buffer containing $0.03 \mathrm{M} \mathrm{NaCl}, 1 \%$ SDS and $0.3 \%$ non-fat dried milk. The hybridization probe was chromosomal DNA from the indicated strain digested with $A l u$ I endonuclease and ${ }^{32} \mathrm{P}$-labelled with the Random Primer DNA Labelling System (Gibco, Life Technologies). The results were scored first by autoradiography and then by cutting the spots and measuring the radiation in a scintillation counter (Beckman). Hybridization levels were calculated as described by Johnson (1991).

Sequencing of the 165 rRNA gene and phylogenetic analysis. DNA from bacterial strains was purified (Sambrook et al., 1989), and the 16S rRNA genes were amplified by PCR using the bacterial primers $27 f$ ( $5^{\prime}$-AGAGTTTGATCMTGGCTCAG-3'), corresponding to positions 8-27 of forward Escherichia coli numbering, and $1492 \mathrm{r}$ (5'-GGTTACCTTGTTACGACTT- $\left.3^{\prime}\right)$, corresponding to positions 1510-1492 of reverse Escherichia coli numbering. The following temperature programme was used: $94{ }^{\circ} \mathrm{C}$ for $5 \mathrm{~min}, 30$ cycles of $94^{\circ} \mathrm{C}$ for $60 \mathrm{~s}, 60^{\circ} \mathrm{C}$ for $60 \mathrm{~s}$ and $72{ }^{\circ} \mathrm{C}$ for $60 \mathrm{~s}$, followed by a final $7 \mathrm{~min}$ incubation at $72^{\circ} \mathrm{C}$. The PCR product was purified using GFX-PCR DNA and a gel band purification kit (Amersham Biosciences) and sequenced completely by using an ABI Prism BigDye Terminator Cycle Sequencing Ready Reaction Kit (PerkinElmer) and an ABI Prism 377 DNA Sequencer (Perkin-Elmer). The 
Table 2. Phenotypic comparison between $K$. cochleae and Enterobacter intermedius strains

1, K. cochleae ATCC 51716; 2, K. cochleae ATCC 51717; 3, Enterobacter intermedius ATCC $33110^{\mathrm{T}} ; 4$, E. intermedius CDC 9011-82; 5, E. intermedius 77-123; 6, E. intermedius 77-136; 7, E. intermedius 77-139; 8, E. intermedius 77-140. Only variable results are shown in the table. The following tests gave identical results for all the strains: triple-sugar iron (acid/acid + gas); motility $(+)$; pigmentation $(-)$; hydrolysis of urea $(-)$ and aesculin $(+)$; utilization of citrate $(+)$ and malonate $(+)$; growth in $\mathrm{KCN}$ broth $(+)$; formation of indole $(-)$, acetylmethylcarbinol $(+)$ and phenylpyruvic acid $(-)$; Møeller's reactions, lysine $(-)$, arginine $(-)$ and ornithine $(+)$; degradation of mucate $(+)$, DNA $(-)$, corn oil $(-)$ and gelatin $(-)$; nitrate reductase $(+)$; fermentation of L-arabinose $(+), \quad$ D-glucose $e^{*}(+)$, L-rhamnose $(+)$, D-xylose $(+)$, cellobiose ${ }^{\star}(+)$, lactose ${ }^{\star}(+)$, maltose $(+)$, trehalose $(+)$, raffinose $(+)$, adonitol $(-)$, glycerol ${ }^{\star}(+)$, myo-inositol $(-)$, D-mannitol $(+)$, D-sorbitol $(+)$, salicin $(+)$, melibiose $(+)$, D-arabitol $(-)$ and methyl $\alpha$-D-glucopyranoside $(+) .{ }^{*}$, Gas determined. Biochemical reactions are reported at $48 \mathrm{~h} ;(+)$, delayed positive reactions $(>48 \mathrm{~h})$.

\begin{tabular}{|c|c|c|c|c|c|c|c|c|}
\hline Test & 1 & 2 & 3 & 4 & 5 & 6 & 7 & 8 \\
\hline ONPG & + & - & + & + & + & + & + & + \\
\hline \multicolumn{9}{|l|}{ Utilization of: } \\
\hline Acetate & + & + & + & + & $(+)$ & + & + & + \\
\hline \multicolumn{9}{|c|}{ Degradation of: } \\
\hline Polypectate & + & + & + & + & $(+)$ & + & $(+)$ & $(+)$ \\
\hline \multicolumn{9}{|c|}{ Fermentation of: } \\
\hline Sucrose & + & + & + & + & $(+)$ & $(+)$ & $(+)$ & + \\
\hline Dulcitol & + & + & $(+)$ & $(+)$ & + & + & + & + \\
\hline Amygdalin & $(+)$ & + & $(+)$ & $(+)$ & $(+)$ & $(+)$ & $(+)$ & $(+)$ \\
\hline
\end{tabular}

obtained 16S rRNA gene sequences were aligned with those of type strains of bacterial genera related to the genus Kluyvera available in the EMBL and Ribosomal Database Project libraries (Maidak et al., 1997) by using the CLUSTAL W program (Thompson et al., 1994) with default parameters and optimized using a multiple sequence alignment editor (Galtier et al., 1996). Phylogenetic trees were constructed by both the neighbour-joining distance method (Kimura two-parameter model and jumble option) and the parsimony character method, using programs contained in the PHYLIP package (Felsenstein, 1989). The stability of the relationships was assessed by bootstrapping (1000 replicates), with programs included in the same package. The sequence of Aeromonas hydrophila ATCC $7966^{\mathrm{T}}$ (GenBank/EMBL/DDBJ accession no. X74677) was used as an outgroup to establish the root of the tree.

\section{RESULTS AND DISCUSSION}

In order to understand the phylogenetic relationships of members of the genus Kluyvera with other members of the family Enterobacteriaceae, the 16S rRNA genes of the type strains of K. cochleae (ATCC $51609^{\mathrm{T}}$ ), K. georgiana (ATCC $51603^{\mathrm{T}}, K$. cryocrescens (ATCC $33435^{\mathrm{T}}$ ) and K. ascorbata (ATCC $33433^{\mathrm{T}}$ ) were sequenced. Also, for reasons to be discussed below, the 16S rRNA gene of the type strain of Enterobacter intermedius (ATCC $33110^{\mathrm{T}}$ ) was sequenced. A phylogenetic tree, constructed using the neighbour-joining distance method, of members of the genus Kluyvera and related genera is shown in Fig. 1.

As can be observed, the four members of the genus Kluyvera clustered together in the tree. However, the type strain of Enterobacter intermedius was included in the Kluyvera cluster very close to the type strain of $K$. cochleae (bootstrap value $100 \%)$. A tree constructed using the parsimony character method was in complete agreement with this (not shown). It should be also pointed out that, according to the base composition of its 16S rRNA gene, Enterobacter intermedius is distantly related to Enterobacter cloacae (similarity value $97 \cdot 4 \%$ ), the type species of the genus Enterobacter, in comparison with its relationship to $K$. cochleae (similarity value $99 \cdot 9 \%$ ). This strongly suggested that, if there was a misclassification of the Enterobacter intermedius type strain, many (if not all) strains of the same species may also be misclassified. A phenotypic analysis (Table 1) showed that Enterobacter intermedius ATCC $33110^{\mathrm{T}}$ is remarkably similar to the type strain of $K$. cochleae and that both strains are Voges-Proskauer-positive, differing from the type strains of the other Kluyvera species. Furthermore, Table 2 shows that this remarkable similarity is not exclusive to the type strains but can be extended to other available independently isolated strains of these two species. The DNA relatedness among the type strains of species in the genus Kluyvera and the type strain of Enterobacter intermedius was also studied (Table 3). As can be observed, this DNA relatedness was higher than the current minimal standard (70\% relatedness) accepted for the phylogenetic definition of a species (Wayne et al., 1987; Stackebrandt \& Goebel, 1994) when labelled DNA from Enterobacter intermedius was used as a probe. However, the DNA relatedness was about $59 \%$ when labelled DNA from $K$. cochleae was used as a probe. This difference may be due to the presence of extrachromosomal DNA in one or both of the reference strains. In agreement with this, Fig. 2 shows that cells of the type strain of Enterobacter intermedius have several high-copy-number plasmids, while the cells of the type strain of $K$. cochleae apparently do not have extrachromosomal elements. Using chromosomal DNA of the type strain of Enterobacter intermedius extracted from gels, the DNA relatedness with the DNA of the type strain of K. cochleae increased to more than $70 \%$ (not shown). Thus, DNA-DNA hybridization assays indicate that the type strains of these bacterial species are included within the same species.

Taken together, these results indicate that Enterobacter intermedius phenotypically and genotypically is a member of the genus Kluyvera. According to Rules 27(2) and 27(3) of the Bacteriological Code, we formally propose to transfer Enterobacter intermedius to the genus Kluyvera as Kluyvera intermedia comb. nov. The species name intermedia is proposed because Latin feminine adjectives must agree in gender with the feminine generic name Kluyvera (Farmer et al., 1981). DNA-DNA hybridization assays indicate that 


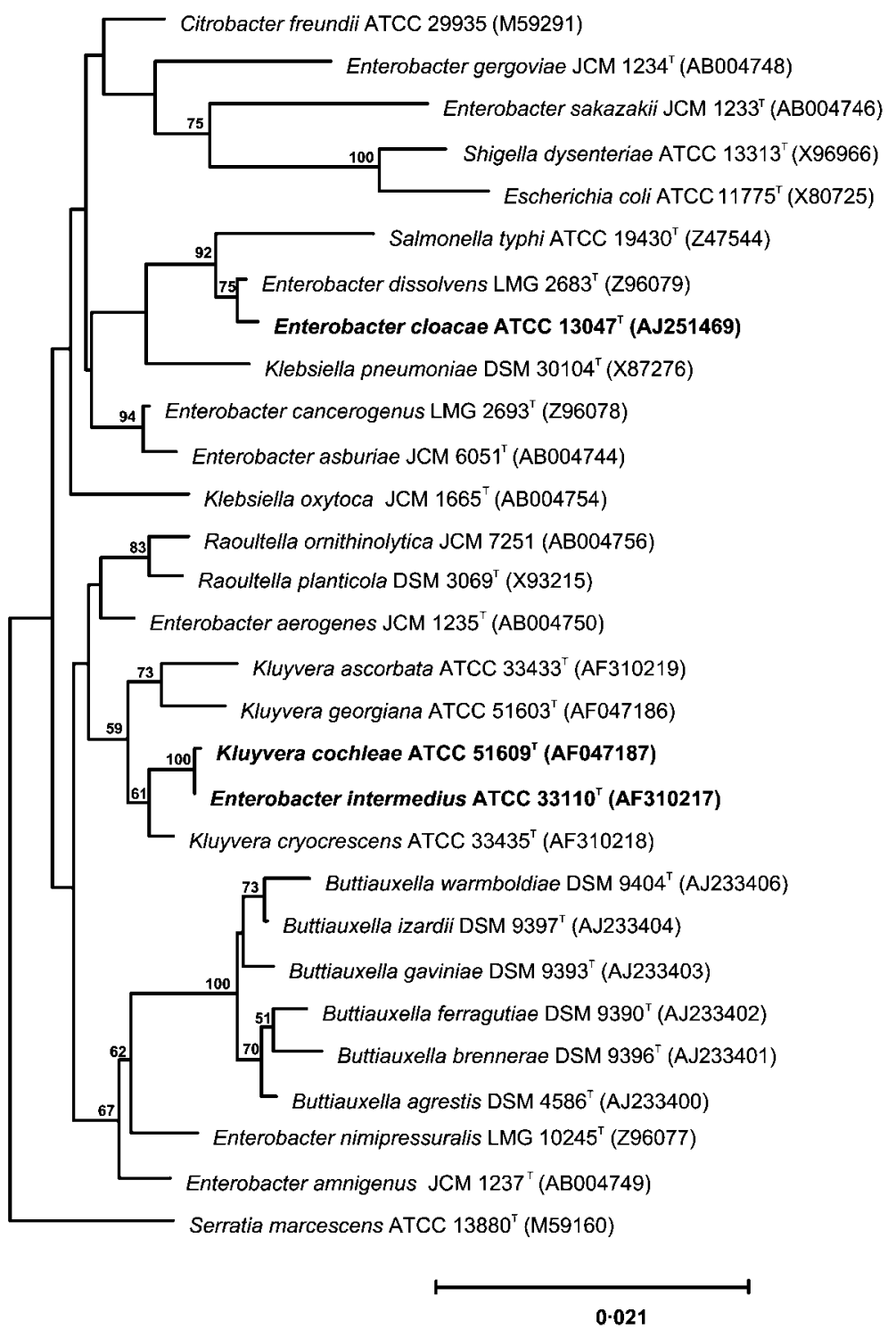

Fig. 1. Phylogenetic tree derived from the analysis of the $16 \mathrm{~S}$ rRNA gene sequences of members of the family Enterobacteriaceae according to the neighbour-joining distance method. The Kimura two-parameter model was used to correct the distances for multiple substitutions at a site. Bootstrap values are from 1000 replications and only those greater than $50 \%$ are shown. Bar, substitutions per nucleotide position.
Table 3. DNA relatedness (\%) among type strains of species of the genus Kluyvera and the type strain of Enterobacter intermedius

1, K. ascorbata ATCC $33433^{\mathrm{T}} ; 2, K$. cochleae ATCC $51609^{\mathrm{T}} ; 3, \mathrm{~K}$. cryocrescens ATCC $33435^{\mathrm{T}} ; 4, K$. georgiana ATCC $51603^{\mathrm{T}}$; 5, Enterobacter intermedius ATCC $33110^{\mathrm{T}} ; 6$, Escherichia coli ATCC $11775^{\mathrm{T}}$ (unrelated control). Results are expressed as the mean of three experiments; standard error $<3 \%$.

\begin{tabular}{|lrrrrrr|}
\hline Labelled DNA probe & $\mathbf{1}$ & $\mathbf{2}$ & $\mathbf{3}$ & $\mathbf{4}$ & $\mathbf{5}$ & $\mathbf{6}$ \\
\hline K. ascorbata & 100 & 16 & 15 & 17 & 19 & 11 \\
K. cochleae & 20 & 100 & 26 & 16 & $\mathbf{5 9}$ & 12 \\
K. cryocrescens & 19 & 23 & 100 & 22 & 29 & 15 \\
K. georgiana & 17 & 18 & 25 & 100 & 14 & 13 \\
Enterobacter intermedius & 21 & $\mathbf{8 9}$ & 30 & 13 & 100 & 16 \\
Escherichia coli & 13 & 13 & 14 & 12 & 14 & 100 \\
\hline
\end{tabular}

$K$. cochleae and $K$. intermedia are heterotypic synonyms. Rule 42 of the Bacteriological Code requires the oldest legitimate epithet be retained. Thus, the oldest legitimate epithet for these taxa is that of Izard et al. (1980). Therefore, $K$. cochleae Müller et al. 1996 is a later synonym of $K$. intermedia (Izard et al. 1980) Pavan et al. 2005.

It is also worth noting that the 16S rRNA gene-based tree presented here strongly suggests that members of the genera Kluyvera and Buttiauxella, as defined by phenotypic assays, are monophyletic, in agreement with the conclusion of a previous report (Spröer et al., 1999). In contrast, members of the genus Enterobacter are intertwined with members of other genera (see Fig. A, available as supplementary material in IJSEM Online), a fact also suggested by trees constructed using groE genes (Harada \& Ishikawa, 1997). This indicates the need for an extensive revision of the phenotypic criteria to classify bacteria within the genus Enterobacter. 


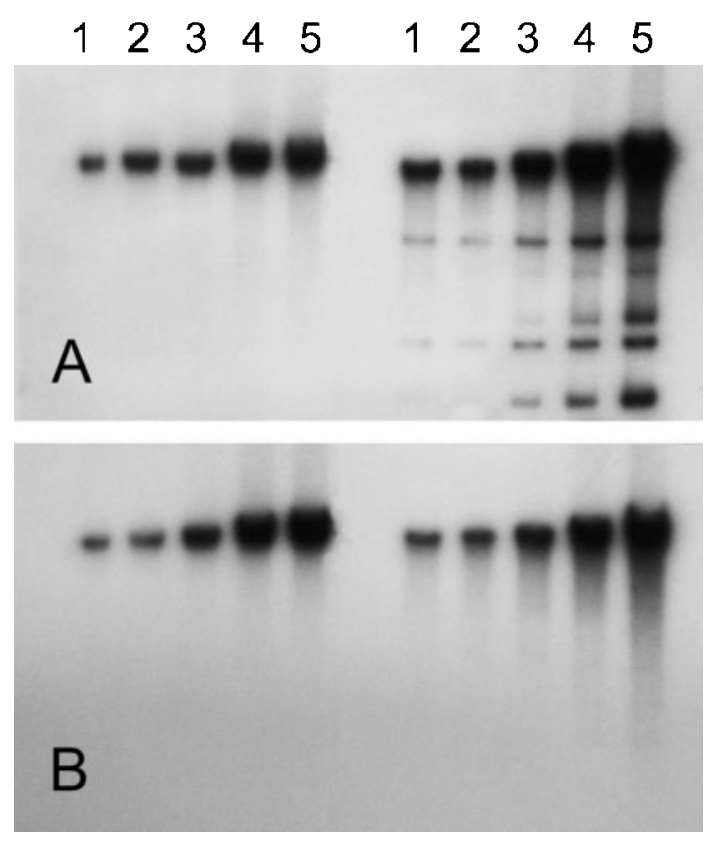

Fig. 2. Southern blot analysis of total DNA extracted from cells of $K$. cochleae ATCC $51609^{\top}$ and Enterobacter intermedius ATCC $33110^{\top}$. (A) Results of the Southern blot analysis when the probe was labelled DNA from Enterobacter intermedius. (B) Results of the Southern blot analysis when the probe was labelled DNA from $K$. cochleae. Lanes 1, 2, 3, 4 and 5 correspond to $2.5,1.25,0.62,0.31$ and $0.15 \mu \mathrm{g}$ of total DNA, respectively.

There is a good correlation between the results of DNADNA hybridization studies presented previously (Farmer et al., 1981) and the results of the phylogenetic analysis presented herein. In both cases, Klebsiella, Enterobacter and Citrobacter species are close relatives of Kluyvera species. Salmonella, Escherichia, Shigella and Erwinia species are intermediate and Proteus and Yersinia species are the most distant relatives among the species analysed in both studies. In the Farmer et al. (1981) analysis, the large heterogeneity of the Enterobacter species observed in our study was also evident.

In conclusion, the results presented herein indicate that there is good agreement between the grouping of species of the genus Kluyvera by $16 \mathrm{~S}$ rRNA gene-based phylogenetic analysis and phenotypic clustering, and that strains of Enterobacter intermedius should be reclassified as proposed since they are by phylogenetic, phenotypic and DNA-DNA relatedness criteria members of the genus Kluyvera. On the other hand, it is clear from this study that extensive studies are necessary to bring about coherence within the genus Enterobacter.

\section{Description of Kluyvera intermedia comb. nov.}

Kluyvera intermedia (in.ter.me'di.a. L. adj. intermedia intermediate).
Basonym: Enterobacter intermedius Izard et al. 1980.

The description is that given by Izard et al. (1980). Some characteristics are as follows. Cells are straight rods, $0 \cdot 5-$ $0 \cdot 7 \times 2-3 \mu \mathrm{m}$, Gram-negative, motile by scant peritrichous flagella. Facultatively anaerobic and chemo-organotrophic, having both a respiratory and a fermentative type of metabolism. Colonies are circular, convex, greyish and smooth on nutrient agar, with growth at 30 and $37^{\circ} \mathrm{C}$. Catalase-positive. Oxidase-negative. Nitrate reductasepositive. Indole-negative. Voges-Proskauer-positive. Acid produced from amygdalin, L-arabinose, cellobiose, dulcitol, D-glucose, glycerol, lactose, maltose, D-mannitol, melibiose, raffinose, L-rhamnose, salicin, D-sorbitol, sucrose, trehalose and D-xylose. Negative for urea hydrolysis. ONPG-positive. Grows in KCN broth. Utilizes citrate and acetate. Does not utilize adonitol, arabitol, erythritol or myo-inositol. Does not degrade gelatin, DNA (DNase-negative) or corn oil (lipase-negative), but degrades mucate. Arginine dihydrolase-negative. Does not form phenylpyruvic acid. Does not produce pigment at $25^{\circ} \mathrm{C}$. Polypeptate-positive. Isolated from molluscs, surface water, soil and a variety of human samples including stool, blood, wounds, bile and a gall bladder.

The type strain is ATCC $33110^{\mathrm{T}}\left(=\mathrm{CIP} 79.27^{\mathrm{T}}=\mathrm{LMG}\right.$ $2785^{\mathrm{T}}=$ CCUG $14183^{\mathrm{T}}$ ).

\section{ACKNOWLEDGEMENTS}

We thank G. Pavan for her technical assistance. This work was partially supported by a grant from the CONICET to J. Z.

\section{REFERENCES}

Abbott, S. L., Cheung, W. K. W., Kroske-Bystrom, S., Malekzadeh, T. \& Janda, J. M. (1992). Identification of Aeromonas strains to genospecies level in the clinical laboratory. J Clin Microbiol 30, 1262-1266.

Abbott, S. L., Cheung, W. K. W. \& Janda, J. M. (2003). The genus Aeromonas: biochemical characteristics, atypical reactions, and phenotypic identification schemes. J Clin Microbiol 41, 2348-2357.

Drancourt, M., Bollet, C., Carta, A. \& Rousselier, P. (2001). Phylogenetic analyses of Klebsiella species delineate Klebsiella and Raoultella gen. nov., with description of Raoultella ornithinolytica comb. nov., Raoultella terrigena comb. nov. and Raoultella planticola comb. nov. Int J Syst Evol Microbiol 51, 925-932.

Farmer, J. J., III, Fanning, G. R., Huntley-Carter, G. P., Holmes, B., Hickman, F. W., Richard, C. \& Brenner, D. J. (1981). Kluyvera, a new (redefined) genus in the family Enterobacteriaceae: identification of Kluyvera ascorbata sp. nov. and Kluyvera cryocrescens sp. nov. in clinical specimens. J Clin Microbiol 13, 919-933.

Felsenstein, J. (1989). PHYLIP - Phylogeny inference package (version 3.2). Cladistics 5, 164-166.

Galtier, N., Gouy, M. \& Gautier, C. (1996). SEAVIEW and PHYLO_WIN: two graphic tools for sequence alignment and molecular phylogeny. Comput Appl Biosci 12, 543-548.

Harada, H. \& Ishikawa, H. (1997). Phylogenetical relationship based on groE genes among phenotypically related Enterobacter, Pantoea, 
Klebsiella, Serratia and Erwinia species. J Gen Appl Microbiol 43, 355-361.

Holt, J. G., Krieg, N. R., Sneath, P. H. A., Staley, J. T. \& Williams, S. T. (1994). Bergey's Manual of Determinative Bacteriology, 9th edn. Williams \& Wilkins.

Izard, D., Gavini, F. \& Leclerc, H. (1980). Polynucleotide sequence relatedness and genome size among Enterobacter intermedium sp. nov. and the species Enterobacter cloacae and Klebsiella pneumoniae. Zentralbl Bakteriol Parasitenkd Infektionskr Hyg Abt 1 Orig Reihe C 1, 51-60.

Janda, J. M., Abbott, S. L., Khashe, S., Kellogg, G. H. \& Shimada, T. (1996). Further studies on biochemical characteristics and serological properties of the genus Aeromonas. J Clin Microbiol 34, 1930-1933.

Johnson, J. L. (1991). DNA reassociation experiments. In Nucleic Acid Techniques in Bacterial Systematics, p.329. Edited by E. Stackebrandt \& M. Goodfellow. Chichester: Wiley.

Maidak, B. L., Olsen, G. J., Larsen, N., Overbeek, R., McCaughey, M. J. \& Woese, C. R. (1997). The RDP (Ribosomal Database Project). Nucleic Acids Res 25, 109-111.

Müller, H. E., Brenner, D. J., Fanning, G. R., Grimont, P. A. D. \& Kämpfer, P. (1996). Emended description of Buttiauxella agrestis with recognition of six new species of Buttiauxella and two species of Kluyvera: Buttiauxella ferragutiae sp. nov., Buttiauxella gaviniae sp. nov., Buttiauxella brennerae sp. nov., Buttiauxella izardii sp. nov., Buttiauxella noackiae sp. nov., Buttiauxella warmboldiae sp. nov., Kluyvera cochleae sp. nov., and Kluyvera georgiana sp. nov. Int J Syst Bacteriol 46, 50-63.

Sambrook, J., Fritsch, E. F. \& Maniatis, T. (1989). Molecular Cloning: a Laboratory Manual, 2nd edn. Cold Spring Harbor, NY: Cold Spring Harbor Laboratory.

Spröer, C., Mendrock, U., Swiderski, J., Lang, E. \& Stackebrandt, E. (1999). The phylogenetic position of Serratia, Buttiauxella and some other genera of the family Enterobacteriaceae. Int J Syst Bacteriol 49, 1433-1438.

Stackebrandt, E. \& Goebel, B. M. (1994). Taxonomic note: a place for DNA-DNA reassociation and 16S rRNA sequence analysis in the present species definition in bacteriology. Int J Syst Bacteriol 44, 846-849.

Thompson, J. D., Higgins, D. G. \& Gibson, T. J. (1994). CLUSTAL W: improving the sensitivity of progressive multiple sequence alignment through sequence weighting, position-specific gap penalties and weight matrix choice. Nucleic Acids Res 22, 4673-4680.

Wayne, L. G., Brenner, D. J., Colwell, R. R. \& 9 other authors (1987). International Committee on Systematic Bacteriology. Report of the ad hoc committee on reconciliation of approaches to bacterial systematics. Int J Syst Bacteriol 37, 463-464. 